\title{
O DESENVOLVIMENTO NORMAL DA PREENSÃO
}

THE DEVELOPMENT OF NORMAL PREHENSION

Pessia Grywac Meyerhof ${ }^{1}$

MEYERHOF, P. G. O Desenvolvimento Normal da Preensão. Rev. Bras. Cresc. Des. Hum., Sao Paulo, IV(2) 1994.

Resumo: O presente trabalho apresenta alguns aspectos importantes do desenvolvimento sensório-motor norma] da preensão relacionados com a evolução desta, partir do bebê recém-nascido. São dadas idéias de comc desenvolver a preensão através de vários tipos de objetos, na sequência do amadurecimento neurológico da criança até 12 meses de idade.

Palavras-chave: preensão, desenvolvimento, bebés.

Summary: This article shows some important aspects of lhe normal sensory-motor development of prehension related lo lhe prehensive evo ution, starting with newborn babies. Some ideas of how lo develop prehension using different kin s of objects are described, respecting the neurological maturation of the child until 12 months of age.

Key-words: prehension, development, babies.

1. Terapeuta Ocupacional. Mestre em Psicologia. Doutoranda em Psicologia Experimental pela Universidade de São Paulo. Treinada na utilização da Escala de Avaliação do Comportamento do Neonato do Brazelton em Boston. Aprovada pela ABRADIMINE para ser Instrutora em Terapia Ocupacional no curso de Tratamento Neuroevolutivo - Bobath e no "Baby Course". Conselheira técnica do Lar Escola São Francisco. Membro do Setor do Desenvolvimento Humano da Disciplina de Pediatria e Neonatologia da Escola Paulista de Medicina. Diretora Clínica da Reabilitação Especializada.

End.: Rua Carlos Millan $7010^{\circ}$ andar, São Paulo - SP, CEP 01456-030 Fone/Fax: (011) 867.8259 


\section{INTRODUÇÃO}

Segundo a teoria da evolução, o homem libertou suas mãos das exigências da locomoção ao passar a andar sobre os dois pés, desenvolvendo, deste modo, uma capacidade manual incomparável.

Para CONNOLY \& ELLIOTT(1981), o homem estaria adaptado a qualquer condição pela força da sua mão, como um instrumento hábil da mente. Seria, provavelmente, o órgão mais elegante e capaz desenvolvido através da seleção natural.

A capacidade manual desenvolve-se, gradativamente, através dos sistemas sensório-motores até atingir a acuidade necessária para que aquele ser específico se adapte. Esta adaptação pode variar e ser modificada cultural e individualmente. Um bebê adquire a precisão da pinça superior (polpa-a-polpa) até cerca de 12 meses de idade; no entanto, se a sua profissão não exigir a utilização desta, por exemplo, um lavrador que ara a sua terra utilizando movimentos globais poderá perder a capacidade de realizar este movimento de pinça. Se necessário, poderá, contudo, readquiri-lo através de autotreinamento.

O desenvolvimento segue uma sequência ordenada e previsível baseada no amadurecimento neurológico e nas oportunidades oferecidas ao bebê. Para observar a preensão deve-se criar um ambiente que permita que a criança inicie e organize movimentos propositais, pois há aprendizagem motora quando as sinergias $\wedge 2$ posturais e motoras são organizadas visando uma tarefa funcional. Por exemplo, ao transferir o peso adequadamente para os membros inferiores, e ficando em pé com base de equilíbrio alargada, o bebê providenciou o "input” tátil, proprioceptivo, necessário para o endireitamento e controle postural. Desta forma, ele libera os braços para alcançar o objeto que deseja, manipulando-o de acordo com suas necessidades. Vê-se claramente, por este exemplo, que a preensão não é um ato isolado, mas sim dependente, entre outros fatores, da volição, da percepção visual e da capacidade motora global da criança.

\section{OBJETIVO}

O objetivo do presente trabalho é mostrar o desenvolvimento normal da preensão de forma didática e prática. Podemos dividi-lo em três partes: - o reflexo de preensão

- o alcance

- a preensão propriamente dita - GRASP

\section{O reflexo de preensão (ou Grasping reflex)}

O reflexo de preensão é definido por KOUPERNIK (1965) como sendo qualquer estímulo dado na palma da mão ou na face palmar dos dedos, provocando o fechamento da mão. Presente em praticamente todos os bebes recém-nascidos, ele fica mais forte aproximadamente aos 30 dias de idade. Tende a diminuir e desaparecer após os primeiros meses (entre 3 e 4 meses de idade).

Suas características principais são: diferenças individuais em relação à força de preensão e em relação à idade em que o reflexo de preensão desaparece; a força deste reflexo é praticamente igual para ambas as mãos de um mesmo bebê. Subsequente à fase reflexa, a preensão voluntária manifesta-se.

O recém-nascido não permanece com a mão fechada, ou seja, com o reflexo de preensão ou em hipertonia. Sua mão vai abrir e fechar, vai tocar o seu corpo e o meio ambiente, recebendo os estímulos táteis e outros estímulos sensoriais, preparando-o para a preensão voluntária.

\section{O alcance (ou aproximação)}

O alcance é a trajetória executada pelos membros superiores na direção de um objeto. Quando o bebê está em decúbito dorsal, entre 3 a 4 meses, o alcance é uma varredura onde o ombro é a única articulação mais móvel. O cotovelo permanece geralmente sernifletido. Os braços estando abduzidos (abertos), o bebê coloca-os na linha média, trazendo consigo o que estiver dentro desta trajetória. Não há tentativa de ajuste dos braços em relação à profundidade. A mão está em plano quase vertical, estando a palma um pouco inclinada para dentro. Ela é trazida como um gancho cego colocado na extremidade de uma vara. A aproximação é feita com a extremidade do braço pela lateral. Em função disto, nesta fase, é importante que os móbiles estejam localizados na altura do peito (esterno) de tal forma que, quando a criança em supino (deitada de barriga para cima) traz seus braços para a linha média ao acaso, estes esbarram no brinquedo. Esse “input” visual e motor começa a desenvolver no bebê noções de atenção visual, coordenação motora, repetição do movimento, noção de profundidade, distancia e outras.

Quando a criança estiver em decúbito lateral é importante que o brinquedo esteja ao alcance do braço, dentro do campo visual da criança, porque estando somente 0 objeto e a mão no campo visual, a criança tentará alcançar o objeto volitivamente.

2 Sinergia é o esforço coordenado de vários órgãos na realização de uma função. 
Entre 5 a 8 meses, ocorre um período intermediário em que o objeto é abordado através de uma trajetória parabólica descrita pelo braço. Com maior domínio da mobilidade do ombro, o cotovelo realiza um movimento de extensão que permite a movimentação antero-posterior do braço. Nesta fase, os brinquedos podem estar colocados em qualquer posição sobre uma base; quando pendurados, devem estar ao alcance da criança quando sentada.

Entre 9 a 12 meses, o alcance é direto, pondo em jogo o ombro, o cotovelo e as articulações do punho e da mão. O bebê já tem o domínio da posição sentada e, conseqüentemente, é capaz de ajustar com precisão o movimento de seu braço prolongado pelo indicador que aponta. O componente dinamico corresponde à rotação do tronco. O ombro do lado da preensão avança resultando em uma aproximação que é a mais evoluída. Nesta fase, o brinquedo pode estar em qualquer lugar do meio ambiente porque o beba já se locomove, de gato, ou em marcha apoiada, ou em marcha independente, indo atrás do objeto.

O suporte de tais características podem estar nos mais diversos objetos, desde brinquedos comercializados até objetos de sucatas.

\section{A preensão propriamente dita (GRASP)}

A preensão é dividida em 4 períodos, sendo considerada preensão propriamente dita (GRASP) quando o objeto é apreendido com a mão.

$1^{\circ}$ período: preensão cúbito palmar (4 meses): é feita entre a primeira falange do mínimo e a eminência hipotenar. A preensão é feita em distancia fixa porque o cotovelo ainda não é funcional. É uma preensão fraca e de curta duração. O bebê abre a mão soltando o objeto que segura, rapidamente. Pode ser bimanual e simultanea (simetria em espelho). O eixo transversal da mão permanece no plano vertical. Esta preensão é feita pelos três últimos dedos contra a palma da mão. Enquanto no alcance foi enfatizado a localização do brinquedo, aqui, o aspecto importante é o seu tipo. Suas características seriam cores contrastantes, com brilhos variaveis para facilitar a atenção visual; texturas variaveis estimulariam o sentido tátil e sensorial; sons da voz humana até sons emitidos por brinquedos de sopro, corda e outros, são importantes para que a criança vire a cabeça para a fonte sonora e, caso a mão e o brinquedo estejam no seu campo visual, possa alcançá-lo e pegá-lo, estando ele no tamanho adequado.

$2^{\circ}$ período: preensão palmar simples ou de aperto (5 a 6 meses): Neste período são utilizados os quatro últimos dedos e a palma da mão com adução do polegar. Este corresponde ao período intermediário de alcance, caracterizado pelo jogo do ombro e extensão do cotovelo. O eixo transversal da mão está em plano horizontal. Quando o bebe quer pegar um objeto pequeno (6 meses), ele raspa a superfície da mesa com os quatro últimos dedos como um rastelo. E importante que o brinquedo oferecido seja constituído de vários tamanhos, texturas, formas e cores diferentes, permitindo que o bebé o segure com seus dedos contra a palma de sua mão, balançado-o, levando-o à boca e jogando-o para o chão, desenvolvendo, desta forma, as noções de percepção de peso, de distancia, de posição e outras. Nesta fase, os bebes começam a passar o objeto de uma mão para outra, de uma forma não especular, simétrica, ou seja, cada mão executa uma ação de modo dissociado.

$3^{\circ}$ período: preensão rádio-palmar $(7$ a 8 meses): o polegar entra em ação pela primeira vez. O polegar é aduzido em direção ao indicador. Aparece o que GESELL (1969) chama de preensão fina ou pinça inferior ou em chave. Passa o objeto de uma mão para outra; a direita diferencia-se da esquerda e a completa. Mantém um objeto em cada mão. A necessidade de experimentar o jogo entre o tônus dos agonistas-antagonistas de uma mão não compromete o tônus da outra mão. Ocorre o início do jogo manipulativo. Abre a mão quando o objeto entra em contato com uma superfície firme (relaxamento dos flexores). Brinquedos que possam ser batidos um contra o outro; com corda para ser puxada e com circunferências menores e mais finas, reforçando os adutores (o fechamento) do polegar, são indicados para esta idade.

$4^{\circ}$ perrodo: preensão rádio-digital ou preensão em pinça superior (9 meses em diante): a coordenação ativa das percepções proprioceptivas cinestésicas e exteroceptivas visuais levam a um desenvolvimento mais econômico do gesto até alcançar o objeto. $\mathrm{O}$ alcance é direto e todas as articulações participam. No início, a sinergia entre os extensores e os flexores é imperfeito, e a criança ainda não tem uma representação exala do tamanho do objeto a ser pego, abrindo exageradamente a mão antes de alcançálo. A individualidade da pinça vai adquirindo mais precisão; a criança, no início do segundo ano de vida, forma a pinça no ar e os 3 últimos dedos ficam dispostos como degraus de uma escada ascendente desde o dedo médio até o dedo mínimo, com extensão das primeiras falanges e semiflexão das outras. Esta extensão permite dar uma grande precisão à delicada flexão do indicador ${ }^{3}$. Posteriormente, há a individualização do indicador em relação

3 O indicador possui este nome porque é o dedo que aponta e toca o objeto a ser pego, por ser mais rico em terminações sensitivas. 
aos outros dedos. Os favorecedores do desenvolvimento da preensão nesta fase são: materiais mais maleáveis com texturas diferentes, incluindo alimentos para serem levados à boca; brinquedos com buracos e saliencias para explorar; folhear revistas, livros etc.; objetos pequenas, como cereais, fios de espessuras diferentes para pegar e soltar; brinquedos que propiciem movimentos repetitivos de soltar, tais como: blocos, caixas (com e sem tampas), bolas de tamanhos diferentes. Este conjunto propicia o amadurecimento global da criança e, principalmente, a dissociação dos dedos e o cálculo da força muscular necessária para a apreensão daquele objeto específico.

Em resumo: do quarto ao sétimo ou oitavo mês, a preensão é essencialmente palmar. A pinça superior se efetua apenas no final do primeiro ano, quando é realizada a oponência. Este falo, além de ter grande significado motor, constitui um acontecimento importante no campo da sensibilidade e da análise: até então, o bebe levava todo objeto à boca. A riqueza das terminações sensitivas das mucosas bucais permitiam uma "informação do mundo externo", segundo THOMAS (1963). De agora em diante, a criança poderá explorar a constância, a forma, a superfície, a temperatura dos objetos e do seu próprio corpo com a ponta dos dedos, e com a ajuda da visão, criar verdadeiros engramas4 que precedem os simbolos lingüfsticos da fase seguinte.

O reflexo de preensão é descrito através de dois componentes: um que fecha a mão - o reflexo de preensão propriamente dito, e outro, estático, proprioceptivo, da persistência da preensão tónica. O primeiro desaparece aproximadamente entre o terceiro e quarto mês de vida, e o segundo desaparece ao final do primeiro ano. Até então, o beba deixava cair o objeto que segurava involuntariamente ou o soltava ao colocá-lo em uma superfície firme, realçando o relaxamento dos flexores pela ação mecanica (7-8 meses). A partir dos 10-11 meses de idade, a coordenação entre os músculos flexores e extensores da mão começa a equilibrar-se: a criança abre a mão voluntariamente, consegue dar um objeto, colocá-lo numa bacia.

\section{CONCLUSÃO}

O desenvolvimento da preensão é nitidamente cefalo-caudal. E iniciada de forma esquemática pelo ombro. Nas primeiras fases, a mão é transportada passivamente, seu movimento é determinado pela movimentação do ombro. O resto do corpo atua como platéia e a mão utiliza o segundo componente do reflexo de preensão (persistenciado tônus flexor sob o efeito do alongamento dos tendões flexores pelo objeto mantido). Esta preensão palmar coloca em jogo uma força muito superior aos seus objetivos, constatada pela flexão total dos dedos (interfalangiana e metacarpofalangianas). As mãos acham o caminho mais curto, económico e com maior acuidade motora para apreender o objeto voluntariamente, satisfazendo seus desejos. A repetição e a variabilidade dos movimentos irão desenvolver maior destreza manual. Aos 12 meses de idade a criança, através das mãos, determina o jogo completo das articulações dos membros superiores. Finalmente, a flexão ativa é metacarpofalangiana: um ato cortical, distal, radial, sinérgico (colaboração dos agonistas e antagonistas), pluriperceptivo (informações exteroceptivas e proprioceptivas).

Aos 4 meses, na ausência da mão no campo visual em conjunto com o objeto, o bebe tentará pegar o objeto com movimentos de protusão de lábios. O falo de o ambiente não ter propiciado a simultaneidade do aparecimento da mão e do objeto no campo visual do bebé, impede-o de exercitar uma capacidade para a qual está preparado. Nesta medida, a adequação da capacidade de manipulação em conjunto com o tipo de objeto para brincar, favorece este encontro criança - habilidade ambiente, cujo produto será o desenvolvimento pleno. Os brinquedos, por sua vez, podem ser confeccionados com sucatas, materiais de uso diário, etc.. Não é importante o brinquedo em si, mas como a criança utiliza-o durante as brincadeiras.

Este trabalho, enfocando o desenvolvimento normal da preensão, faz-se didaticamente, dentro da evolução das etapas do desenvolvimento normal. Sabese que quando há lacunas dentro desta evolução, durante a primeira infancia, existe a possibilidade da criança apresentar problemas na escolaridade. Pode acontecer que o bebe tenha dificuldade em alcançar um objeto que Ihe é apresentado. Seria um problema emocional ou de falta de interesse? Ou talvez um problema visual, ele não enxerga adequadamente o objeto ou não tem noção da distancia deste em relação ao seu corpo (percepção visual falha?); ou ainda poderia ser uma incapacidade sensório-motora: ele vê o objeto, tem interesse e vontade de pegá-lo, mas não tem a capacidade motora para tal aio, porque há grande tensão muscular na cintura escapular que não permite que os braços venham para frente. $\mathrm{E}$ necessário verificar qual a causa do problema que está impedindo que aquele bebe específico consiga alcançar o brinquedo, tratá-lo antes que este se consolide ou seja compensado através de vícios

4 Engrama é um traço de memória (fisiológico e herdada) proveniente de um ou de urna atividade do sistema nervoso (DREVER, 1973). 
de posturas ou de outras maneiras que, somada a outros prováveis problemas, possam interferir na posterior alfabetização adequada.

Para finalizar, queremos enfatizar que se trata de um bebe total, interagindo através da preensão com outros seres e ambientes, recebendo e dando, preparando-se, deste modo, para uma boa qualidade de vida dentro de sua realidade.

\section{AGRADECIMENTO}

À aplaine Pedreira Rabinovich pela colaboração na elaboração deste artigo.

\section{BIBLIOGRAFIA}

CONNOLLY, K.; ELLIO11, E. J. Função da mão. In: JONES, N. B. Estudos etológicos do comportamento da criança. São Paulo, Ed. Enio Matheus Guazelli \& Cia. Ltda, 1981.

DREVER, J. A dictionary of psychology. Middlesex, Penguin Book Ltd.,1973.

THOMAS, A. Behavioural individuality in early childhood. N. Á. Univ. Press., 1963.

recebido em: 05/04/95 aprovado em: 31/05/95 